\title{
A CAVERNA DE PLATÃO EM TRÊS ATOS
}

\author{
PLATO'S CAVE IN THREE ACTS
}

Natalia Costa Rugnitz*

\section{RESUMO:}

O texto que segue tem o objetivo de ensaiar uma reconstrução dramática da Alegoria da Caverna, presente no sétimo livro da República de Platão. Proporemos uma divisão em três atos, sendo o primeiro composto pela descrição (i) do lugar da encenação como uma prisão e (ii) a condição das personagens como prisioneiros; o segundo, composto pela descrição (i) da instância de libertação de um dos cativos e (ii) dos avatares do caminho para fora da caverna por ele percorrido; o terceiro, composto pela descrição do processo que leva à volta à caverna. Proporemos, nesta base, um esboço do arco de transformação da personagem do prisioneiro liberado na sequência (i) prisioneiro, (ii) liberto, (iii) sujeito esclarecido, (iv) redentor e, finalmente, (v) mártir. Sugeriremos a existência de (i) dois pontos de giro da trama e (ii) dois deus ex machina, procurando destacar o caráter trágico da construção.

PALAVRAS-CHAVE: Conhecimento. Opinião. Ignorância. Modelo. Cópia.

ABSTRACT: The text that follows aims to offer a dramatic reconstruction of the Allegory of the Cave, present in the seventh book of Plato's Republic. We will propose a division into three acts, the first consisting of the description (i) of the staging place as a prison and (ii) the condition of the characters as prisoners; the second, consisting of the description (i) of the instance of liberation of one of the captives and (ii) of the avatars of the way out of the cave he performs; the third, composed by the description of the process of returning to the cave. On this basis, we shall propose an outline of the transformation arc of the character of the released captive in the sequence (i) prisoner, (ii) freed, (iii) enlightened subject, (iv) redeemer and finally (v) martyr. We will suggest the existence of (i) two turning points of the plot and (ii) two deus ex machina, highlighting the tragic character of the construction and offering. KEY-WORDS: Knowledge. Opinion. Ignorance. Original. Copy.

\section{INTRODUÇÃO}

No início do Livro VII da República, Sócrates anuncia que irá descrever a situação humana em relação à inteligência ou, melhor, à educação ( $\pi \alpha 1 \delta \varepsilon i ́ \alpha \varsigma)$ e à sua falta

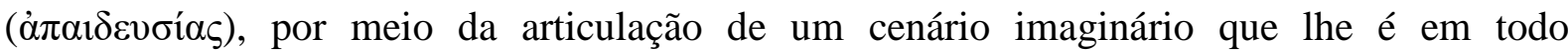
semelhante. Assim, utilizando a alegoria como recurso, Platão oferecerá ao leitor uma lição filosófica na forma de uma construção literária da mais fina elaboração. A nossa proposta hoje

\footnotetext{
* Licenciada en Humanidades - Filosofía (Universidad de Montevideo, Uruguay). Mestre em Filosofia Antiga (Unicamp). Doutoranda em Filosofia Antiga (Unicamp). E-mail: natalia.costa.rugnitz@gmail.com.
} 
será encarar a Alegoria da Caverna (PLATÃO, República (REP), 514a et seq.) desde o ponto de vista dramático, ensaiando uma reconstrução da passagem a partir dos cânones clássicos da composição - aos quais, por fortuna, a figura se adéqua perfeitamente. Destarte, além do prólogo ${ }^{1}$ teremos a divisão em três atos, separados por dois nós da trama e que se rematam em uma resolução a modo de epílogo; teremos, assim mesmo, clímax e anticlímax, e personagens com contornos nítidos e definidos. O objetivo da proposta será colocar à disposição da comunidade filosófica um "esboço de roteiro", com o fim de desenvolver, posteriormente e caso a proposta venha a ser aceita, um plano de trabalho conjunto e multidisciplinar visando a pôr em cena o memorável trecho, motivados fundamentalmente pela potencial valência pedagógica e social da iniciativa.

\section{PRIMEIRO ATO: OS PRISIONEIROS DA CAVERNA}

O quadro pintado por Sócrates é assaz conhecido. Há uma caverna sob a terra, ligada à superfície por um corredor longo, íngreme e estreito. Esse corredor se abre por um lado à intempérie e, pelo outro, se aprofunda no chão e se remata em uma abóbada no subsolo, aonde não chega a luz do dia. A caverna é, portanto, um recinto subterrâneo escuro e, cabe adiantar, de importantes dimensões: não tanto do tamanho do calabouço mas - pelo que está a acontecer ali - algo com o espírito do calabouço, mas o tamanho do teatro ou a catedral.

No fundo da gruta há homens acorrentados, sujeitos das extremidades e o pescoço por pesados grilhões que os fincam ao terreno. Completamente reduzidos, impedidos inclusive de girar a cabeça, os prisioneiros permanecem imóveis na escuridão, olhando compulsória e fixamente para frente. Eles estão ali desde a infância, diz Sócrates (REP, 514a); criados em cativeiro e sem experimentar jamais nada distinto daquilo, os cativos apresentam de fato uma passividade natural. É importante destacar, com efeito, que, apesar de haver escravos no interior da Caverna - ou condenados, ou penitentes - não há rebelião no subsolo; os prisioneiros, pelo contrário, afrontam a circunstância com uma mansa naturalidade.

\footnotetext{
${ }^{1}$ A inclusão do prólogo como uma "explicação prévia" é, segundo Nietzsche (1999, XII, p. 81), um agregado racionalista tipicamente socrático à estrutura primitiva da tragédia (cujos paradigmas são Esquilo e Sófocles) que empobreceu a experiência trágica tradicional e foi mais um sintoma da decadência geral da cultura grega suscitada por Sócrates. O prólogo de Eurípedes e o inteiro fenômeno da Nova Comédia Ática têm, segundo Nietzsche, estas conotações. A “introdução”, apesar do seu caráter sucinto (no qual Sócrates anuncia apenas que irá descrever a situação humana originária em relação à educação e à sua falta), pode ser lida como a forma que o prólogo assume na Caverna e, assim, como um traço típico do caráter da personagem Sócrates que condiz com a posição a respeito das artes avançada em outras partes do diálogo.
} 
No interior do recinto, uma curiosa engenharia ergue em volta dos cativos um espetáculo peculiar. Às costas dos prisioneiros há um muro, um "tabique do tipo daqueles por sobre os que mágicos ou titereiros mostram seus marionetes" (REP, 514b). Nos bastidores, para além do muro, há ardendo uma fogueira, e entre o muro e a fogueira circula uma estranha procissão de homens carregando diversos objetos e figuras e dialogando entre si. A dinâmica final é similar à de um teatro de sombras: o fogo ilumina os objetos transportados e suas sombras se projetam, por cima do muro, na parede adiante dos cativos.

A Caverna é então, ao que parece, um palco; o que está a acontecer ali dentro, um espetáculo sinistro; os cativos, uma patética plateia. Desde a plateia não é possível divisar os bastidores: desde ali se veem somente as sombras deturpadas das marionetes no fundo da caverna. No entanto, e dada a acústica do recinto, os espectadores escutam o ecoar dos nomes com que os homens da procissão se referem aos objetos que carregam e repetem esses nomes. Assim, eles aprendem a se comunicar nas trevas. Como crianças, na total ingenuidade, eles brincam de adivinhar qual sombra virá depois de qual, celebrando em inusitada alegria quem se revela mais destro na competição. A plateia, então, se diverte. "Estranhos prisioneiros", anota Gláucon; "são como nós”, responde Sócrates (REP, 515a).

\section{PRIMEIRO NÓ DA TRAMA: DE PRISIONEIRO A LIBERTO}

Após ter descrito a topologia da caverna e a condição dos habitantes, Sócrates convida seus interlocutores a imaginar o que aconteceria se um dos prisioneiros fosse libertado e conduzido para fora. Eis o fim do primeiro ato e o primeiro nó da trama, que na nossa reconstrução consideraremos um deus ex machina. O deus ex machina é um artifício utilizado no teatro antigo no qual um acontecimento novo e inesperado é introduzido na cena por meio de guindastes ou artifícios semelhantes com o fim de mudar inusitadamente o rumo dos acontecimentos. Nada do descrito no primeiro ato, isto é: nada do que acontece no interior da caverna, nenhum dos avatares do espetáculo nem impulso algum surgido da subjetividade dos prisioneiros explica a mudança de cenário, isto é, a saída da caverna; o vocabulário da coerção e da violência é, ao invés, manifesto neste ponto², e Platão é claro: não há movimento

\footnotetext{
${ }^{2}$ O léxico da violência é notável não só nesse momento, mas na totalidade da alegoria. Ver: $\lambda v \theta$ cín

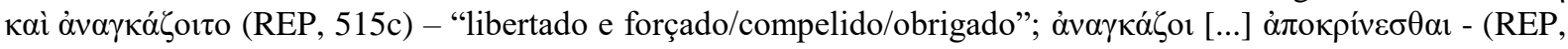
515d) "forçado/compelido/obrigado a responder"; $\alpha \dot{\alpha} \alpha \gamma \kappa \alpha ́ \zeta o l] ~ \beta \lambda \varepsilon ́ \pi \varepsilon ı v$ (REP, 515e) "forçado/compelido/obrigado

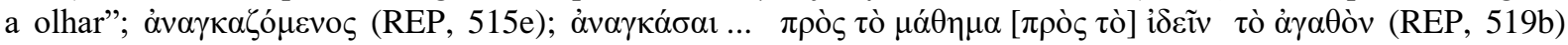

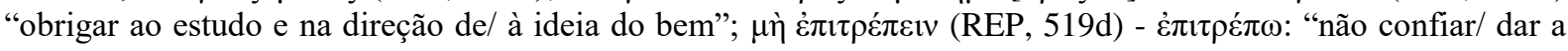


algum da vontade própria na instância de libertação do prisioneiro. Como seja, o fato é que o prisioneiro devém liberto e que, com isso, o percurso dramático dá um giro e tem início o segundo ato.

\section{SEGUNDO ATO: A SAÍDA DA CAVERNA}

O segundo ato se inicia, então, com um dos prisioneiros sendo libertado e impelido a levantar-se e andar em direção à luz. Ao encarar o brilho da fogueira, ele sentiria dor nos olhos e sua vista ficaria deslumbrada, incapaz de distinguir o que há em volta. Se nessas circunstâncias alguém lhe apresentasse os bonecos e utensílios cujas sombras ele via antigamente na morada subterrânea e o obrigasse, "à força de perguntas" (REP, 515b), a chamar cada um deles pelo nome, o liberto ficaria confuso e sem palavras. Com a mente atordoada e a visão embaçada, ele seria incapaz de reconhecer os artifícios do cenário ou de compreender o que está a acontecer, muito menos de dar conta dos sucessos ou de acreditar estar em bom caminho. Pelo contrário, ele tentaria evitar a luz e voltar dos bastidores ao seu assento na plateia. Se, nesse momento, a força externa o empurrasse novamente, "arrastandoo à força pela rampa rude e empinada" (REP, 515C), ele se revoltaria e sofreria mais ainda.

Contudo, são dores de parto. Ao atravessar a boca da caverna, o liberto se acostumaria pouco a pouco. No começo, exploraria a intempérie nas horas da noite, pousando o seu olhar sobre as sombras dos objetos naturais às quais é receptivo pela vida prévia na caverna. Depois, como farejando o resplendor, se deteria nos reflexos na água e nas superfícies espelhadas, seguindo o rasto da claridade até ser capaz de divisar "o céu e o próprio céu", "a lua e as estrelas" (REP, 516a). Após a "fase noturna", guiado já por uma visão despejada e uma lucidez florescente, a aurora coroaria o percurso fatalmente, e o liberto experimentaria a luz do dia.

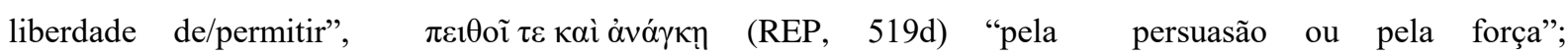

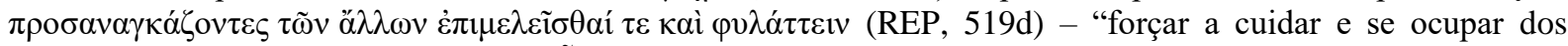

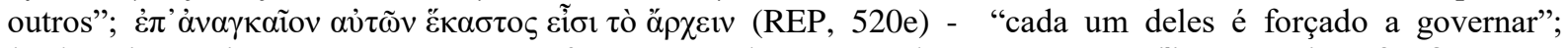

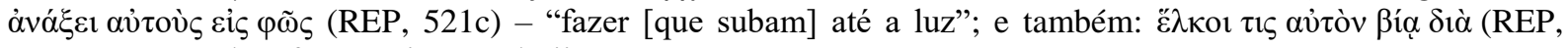

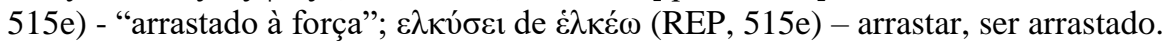




\section{CLÍMAX: A EMANCIPAÇÃO DAS TREVAS - DE LIBERTO A ILUMINADO}

Semelhante neste ponto ao iniciado, e revelando-se mais perspicaz do que poderia acreditar-se considerando seu passado, o liberto se encontraria então no espaço diurno a céu aberto. Dirigindo a vista ao alto descobriria o Sol, observaria que ele "rege as estações" e a physis no seu conjunto, o reconheceria como "fonte da verdade e da vida" e "de algum modo como [...] a causa" (REP, 516b) do que ele e seus companheiros estavam habituados a enxergar. Assim, concluiria finalmente que esse universo diáfano, solar e luminoso é o mundo verdadeiro, e não aquele claustro no subsolo, que deixara atrás. Nesse instante, o liberto atingiria a completa emancipação das trevas e gozaria da contemplação e da claridade na Ilha dos Bem-aventurados, como lhe chama Sócrates. Eis o clímax da Caverna.

\section{SEGUNDO NÓ DA TRAMA: A VOLTA À CAVERNA (VIÉS POLÍTICO)}

Mas as peripécias não acabam aqui. Na sua contemplação, o iluminado pensa para si que "preferiria, como Aquiles, sofrer qualquer destino a ter que voltar a viver no subterrâneo com os seus antigos companheiros" (REP, 516c-d). Mas Sócrates é rigoroso e, chegado esse ponto, propõe um novo giro para os acontecimentos: "Uma vez atingida a região superior", diz Sócrates, em relação ao esclarecido, "e após ter suficientemente contemplado o bem, não o deixaremos [...] permanecer lá em cima" (REP, 516c-d). O liberto deverá voltar e assistir os prisioneiros, libertando-os por sua vez daquele mundo tenebroso, como ele mesmo fora libertado. Mais uma vez, por conseguinte, Platão introduz aqui uma potência exógena que atua com violência semelhante à primeira e muda o rumo "natural" dos acontecimentos. $\mathrm{O}$ liberto, ainda que emancipado das trevas e esclarecido, não é homem livre. Assim, o iluminado se transforma em redentor, volta às trevas e se inicia o terceiro e último ato.

Na sua viagem de regresso, diz Sócrates, o redentor sofrerá dores paralelas às da ascensão: sua visão ficará ofuscada, agora por causa da penumbra, e lhe será necessário um segundo tempo de adaptação para habituar-se novamente ao claustro. Chegado lá, acostumado já às meias-luzes e conhecedor não só da encenação mas dos peculiares bastidores do espetáculo, o redentor relatará sua experiência aos antigos companheiros: ele narrará a saída da caverna e dará notícia do mundo luminoso para além da grota, revelando aos cativos sua condição de escravos e instando-os a libertar-se dos grilhões também eles e embarcar o quanto antes no caminho para fora. 


\section{ANTICLÍMAX: DE REDENTOR A MÁRTIR}

O redentor não terá, no entanto, uma fortuna de glória mas de martírio. Ao relatar sua aventura, os outros pensarão que perdeu o juízo e que estragou os olhos na viagem para fora, mofando-se dele e tachando-o de louco (REP, 517a): o Sol que ele descreve, e a água e sua superfície de espelho e a noite e o céu noturno, serão, de fato, absolutamente inconcebíveis para os prisioneiros. A desconfiança dos cativos, não obstante, surgirá não apenas da ilusão que os hipnotiza e da obstinação que provoca neles o feitiço que padecem, mas da própria incapacidade do redentor de explicar de um modo compreensível a sua descoberta. E esse é um detalhe que não pode passar despercebido. Platão diz, com efeito, que, chegada a hora derradeira o redentor, cuja única ferramenta é a linguagem, ficaria sem palavras: o que é esse Sol que ele venera? O que é esse mundo do lado de fora da caverna? Não há comunicação suficientemente persuasiva, pois se trata de universos em grande medida incomensuráveis.

\section{EPÍLOGO}

Se então o redentor, perante a insuficiência do seu método, procurasse libertar os prisioneiros à força e arrastá-los para cima, aconteceria fatalmente que, "caso fosse possível [aos prisioneiros] fazer uso das mãos e matá-lo, o matariam" (REP, 517a). Eis o anticlímax da caverna. E assim chegamos ao epílogo da história.

\section{REFERÊNCIAS}

NIETZSCHE, Friedrich. O nascimento da tragédia, ou Helenismo e Pessimismo. 2. ed. Tradução e notas de J. Guinsburg. São Paulo: Companhia das Letras, 1999.

PLATÃO, Republic, Plato in Twelve Volumes. Tradution Paul Shorey, Cambridge: Harvard University Press, 1969.

PLATÃO, República. Tradução Carlos Alberto Nunes, edição bilíngue grego-português. Belém: Ed. da Universidade Federal do Pará, 2016. 